\title{
Nonclinical Trial Phase
}

National Cancer Institute

\section{Source}

National Cancer Institute. Nonclinical Trial Phase. NCI Thesaurus. Code C124280.

A distinguishable part or stage in a nonclinical study. 